\title{
Conditional Ablation of Striatal Neuronal Types Containing Dopamine D2 Receptor Disturbs Coordination of Basal Ganglia Function
}

\author{
Hiromi Sano, ${ }^{1,2}$ Yasunobu Yasoshima, ${ }^{1}$ Natsuki Matsushita, ${ }^{1}$ Takeshi Kaneko, ${ }^{3}$ Kenji Kohno, ${ }^{2}$ Ira Pastan, ${ }^{4}$ and \\ Kazuto Kobayashi ${ }^{1}$ \\ ${ }^{1}$ Department of Molecular Genetics, Institute of Biomedical Sciences, Fukushima Medical University School of Medicine, Fukushima 960-1295, Japan, \\ ${ }^{2}$ Research and Education Center for Genetic Information, Nara Institute of Science and Technology, Ikoma 630-0101, Japan, ${ }^{3}$ Department of Morphological \\ Brain Science, Graduate School of Medicine, Kyoto University, Kyoto 606-8501, Japan, and ${ }^{4}$ Laboratory of Molecular Biology, Division of Basic Sciences, \\ National Cancer Institute, National Institutes of Health, Bethesda, Maryland 20892
}

Dopamine (DA) exerts synaptic organization of basal ganglia circuitry through a variety of neuronal populations in the striatum. We performed conditional ablation of striatal neuronal types containing DA D2 receptor (D2R) by using immunotoxin-mediated cell targeting. Mutant mice were generated that express the human interleukin-2 receptor $\alpha$-subunit under the control of the $D 2 R$ gene. Intrastriatal immunotoxin treatment of the mutants eliminated the majority of the striatopallidal medium spiny neurons and cholinergic interneurons. The elimination of these neurons caused hyperactivity of spontaneous movement and reduced motor activation in response to DA stimulation. The elimination also induced upregulation of GAD gene expression in the globus pallidus (GP) and downregulation of cytochrome oxidase activity in the subthalamic nucleus (STN), whereas it attenuated DA-induced expression of the immediate-early genes (IEGs) in the striatonigral neurons. In addition, chemical lesion of cholinergic interneurons did not alter spontaneous movement but caused a moderate enhancement in DA-induced motor activation. This enhancement of the behavior was accompanied by an increase in the IEG expression in the striatonigral neurons. These data suggest that ablation of the striatopallidal neurons causes spontaneous hyperactivity through modulation of the GP and STN activity and that the ablation leads to the reduction in DA-induced behavior at least partly through attenuation of the striatonigral activity as opposed to the influence of cholinergic cell lesion. We propose a possible model in which the striatopallidal neurons dually regulate motor behavior dependent on the state of DA transmission through coordination of the basal ganglia circuitry.

Key words: motor control; dopamine; dopamine D2 receptor; striatum; medium spiny neuron; immunotoxin-mediated cell targeting

\section{Introduction}

The basal ganglia mediate a wide variety of psychomotor functions, including motor control, motor planning, and behavioral learning (Graybiel, 1995; Schultz et al., 1997). Dopamine (DA)producing neurons, which originate from the substantia nigra pars compacta $(\mathrm{SNc})$ and terminate in the dorsal striatum, play a critical role in basal ganglia functions. The striatum receives convergent excitatory inputs from many cortical and thalamic areas and projects to the output nuclei, including the substantia nigra

Received July 7, 2003; revised Aug. 15, 2003; accepted Aug. 15, 2003.

This work was supported by grants-in-aid from the Ministry of Education, Science, Culture, and Sports of Japan Core Research for Evolutional Science and Technology, Solution Oriented Research for Science and Technology, and Research Institute of Science and Technology for Society of Japan Science and Technology Corporation; Toray Science Foundation; and Uehara Memorial Research Foundation. We thank Drs. T. Nagatsu, H. Sawada, K. Nishii, and T. Kowada for generation of the mutant mice; Drs. S. Nakanishi and S. Kaneko for providing the SP CDNA; Dr. Y. Yanagawa for the GAD67 CDNA; Dr. H. Kawano for the antibody against choline acetyltransferase; and M. Kikuchi for technical support in the behavioral analysis. We are also grateful to Drs. T. Aosaki and W. J. Song for critical reading of this manuscript.

Correspondence should be addressed to Dr. Kazuto Kobayashi, Department of Molecular Genetics, Institute of Biomedical Sciences, Fukushima Medical University School of Medicine, Fukushima 960-1295, Japan. E-mail: kazuto@fmu.ac.jp.

Copyright $\odot 2003$ Society for Neuroscience $\quad$ 0270-6474/03/239078-11\$15.00/0 pars reticulata and the entopeduncular nucleus (Alexander and Crutcher, 1990; DeLong, 1990; Gerfen and Wilson, 1996). Striatal projections are composed of two subpopulations of GABAergic medium spiny neurons that constitute the so-called direct and indirect pathways. The striatonigral spiny neurons in the direct pathway provide monosynaptic inhibition to the output nuclei, whereas the striatopallidal spiny neurons in the indirect pathway inhibit the globus pallidus (GP). The GP neurons send inhibitory efferents to the output nuclei or to the subthalamic nucleus (STN), and the STN provides an alternative route to the output nuclei. The standard model of the neural circuitry suggests that basal ganglia functions are dependent on the balance between opposing inputs from the direct and indirect pathways, although the model is challenged by recent data, such as the presence of the direct corticosubthalamic pathway (Nambu et al., 2002) and the rhythmic pattern of neuronal firing after DA depletion (Bergman et al., 1998; Bevan et al., 2002).

DA modulates excitatory and inhibitory synaptic transmissions in a variety of neuronal populations expressing distinct DA receptor subtypes (Nicola et al., 2000). These subtypes are classified into two classes of receptors, the D1 class (D1R and D5R) and 


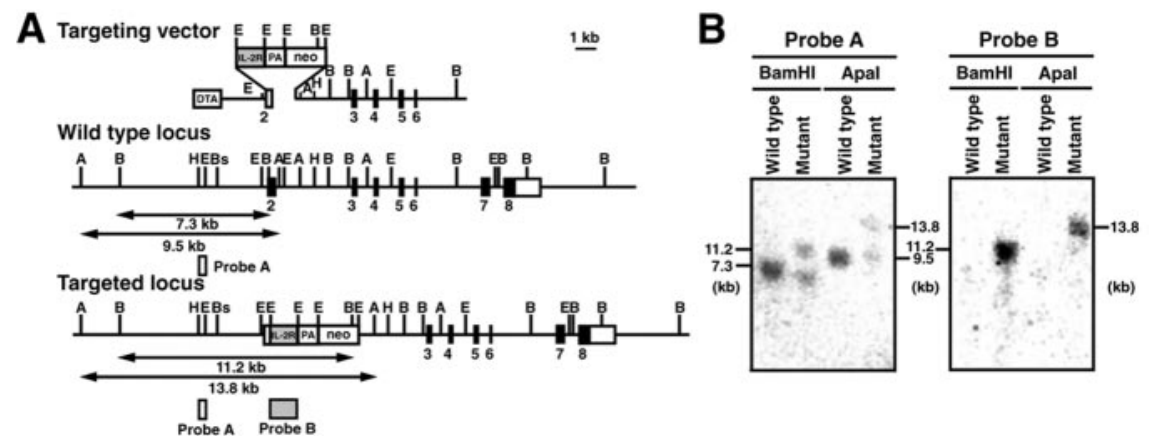

C

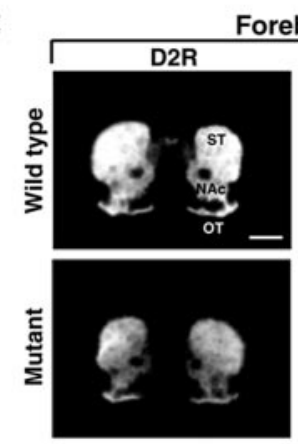

orebrain
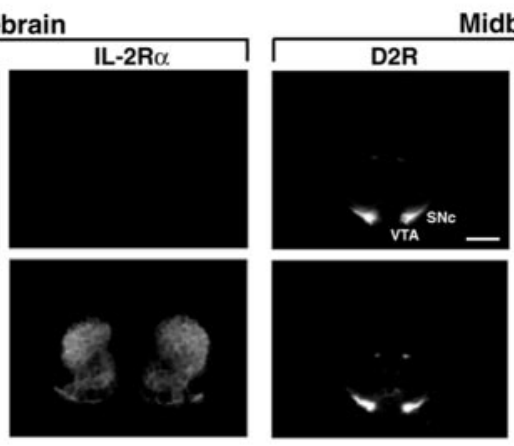

Midbrain

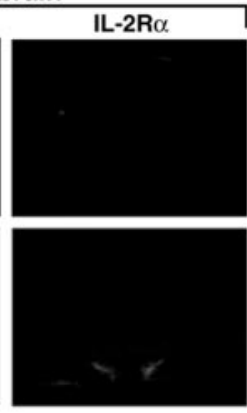

Figure 1. Generation of the mutant mice expressing IL-2R $\alpha$ under the control of the D2R gene. A, Strategy for the knock-in mutagenesis. The targeting vector contains the $5^{\prime}$-homologous region, the human $I L-2 R \alpha$ gene cassette fused to the polyadenylation signal (PA), the phosphoglycerate kinase-1-neo gene cassette (neo), the 3' ${ }^{\prime}$-homologous region, and the diphtheria toxin A-fragment (DTA) gene cassette. The restriction enzyme fragments for Southern blot hybridization are indicated. A, Apal; $B$ BamHI; Bs, BstPI; E, EcoRl; and H, HindIII. B, Genotyping of ES cellular DNA. Genomic DNA from a representative ES clone carrying the targeted mutation and from wild-type cells were digested with the indicated restriction enzymes and subjected to Southern blot hybridization with probe A or B. C, In situ hydridization analysis of IL-2R $\alpha$ expression. Coronal sections ( $10 \mu \mathrm{m}$ thick) through the forebrain or midbrain were used for in situ hybridization with ${ }^{35} \mathrm{~S}$-labeled riboprobe for a mouse D2R or human IL-2R $\alpha$ sequence. ST, Striatum; NAc, nucleus accumbens; 0T, olfactory tubercle; VTA, ventral tegmental area. Scale bar, $1 \mathrm{~mm}$.

the D2 class (D2R, D3R, and D4R) (Civelli et al., 1993). D1R and D2R subtypes seem to be localized in the striatonigral and striatopallidal spiny neurons, respectively (Gerfen et al., 1990; Hersch et al., 1995; Yung et al., 1995), although colocalization of these two subtypes in some spiny neurons has been suggested (Lester et al., 1993; Surmeier et al., 1996). Striatal aspiny interneurons producing ACh or GABA also express different subtypes of DA receptors (Kawaguchi et al., 1995). The cellular mechanism by which DA controls the basal ganglia circuitry through various populations of striatal neurons is not yet fully understood.

Immunotoxin-mediated cell targeting (IMCT) is a transgenic mouse technique to eliminate specific cell types from a complex neural circuitry (Kobayashi et al., 1995a; Watanabe et al., 1998). In the present study, we perform conditional ablation of striatal neurons containing D2R subtype by using IMCT technology. We show that ablation of these neurons eliminates the majority of the striatopallidal medium spiny neurons and cholinergic interneurons. We examine behavioral influences of the cell elimination on basal ganglia function that depends on DA transmission and analyze the neural circuitry involved in the behavior. In addition, we examine the influences of chemical lesion of cholinergic interneurons on basal ganglia function. Our results provide evidence for a key role of the striatopallidal neurons in coordination of the neural circuitry, depending on the state of DA transmission.

\section{Materials and Methods}

Generation of mutant mice. In the strategy of IMCT (Kobayashi et al., 1995a), transgenic mice are generated that express human interleukin-2 receptor $\alpha$-subunit (IL-2R $\alpha$ ) under the control of a cell type-specific promoter. These mice are then treated with a recombinant immunotoxin (IT), which consists of the variable regions of the anti-IL-2R $\alpha$ monoclonal antibody fused to a bacterial exotoxin, resulting in ablation of target cell types. Phage clones containing the mouse $D 2 R$ gene were isolated from a $\lambda$ FIXII genomic DNA library (Stratagene, La Jolla, CA). The targeting vector contained the $5^{\prime}$-homologous region of $2.4 \mathrm{~kb}$, the human $I L-2 R \alpha$ gene cassette (Kobayashi et al., 1995a) fused to the SV40 early gene polyadenylation signal, the phosphoglycerate kinase-1-neo gene cassette, the 3 '-homologous region of $7.6 \mathrm{~kb}$, and the diphtheria toxin A-fragment gene cassette (Fig. 1A). Gene targeting with mouse embryonic stem (ES) cells was performed as described by Kobayashi et al. (1995b). E14 ES cells obtained from the 129/SvJ mouse strain were electroporated with the targeting vector linearized at the proper restriction enzyme site. The ES cell clones were selected in medium containing G418, and the clones carrying the targeted mutation were identified by Southern blot hybridization with the $0.5-\mathrm{kb}$ HindIII-EcoRI DNA fragment containing a part of the $5^{\prime}$-external region of the targeting vector as a probe. These cells were injected into C57BL/6J blastocysts, which were implanted into the uterine horns of ICR pseudopregnant females. Male chimeras were mated with C57BL/6J females. Mice heterozygous for the mutation were backcrossed to C57BL/6J mice for more than five generations. Genotyping was performed by Southern blot hybridization of genomic DNA prepared from tail tissue. Animal care and handling procedures were in accordance with the guideline established by the Experimental Animal Center of Fukushima

Medical University.

Stereotaxic surgery. Mice were anesthetized with sodium pentobarbital $(50 \mathrm{mg} / \mathrm{kg}$, i.p.) and subjected to unilateral or bilateral intrastriatal injection of the recombinant IT. Anti-Tac(Fv)-PE38 (Kreitman et al., 1994) was diluted into a final concentration of $10 \mu \mathrm{g} / \mathrm{ml}$ in PBS containing $0.1 \%$ mouse serum albumin. The IT solution or PBS $(0.5 \mu \mathrm{l} / \mathrm{site})$ was injected into six sites in one side of the striatum through a glass micropipette, which was stereotaxically introduced by using the coordinates according to an atlas of the mouse brain (Paxinos and Franklin, 2001). The anteroposterior, mediolateral, and dorsoventral coordinates from bregma and dura were 1.20/1.25/2.00 mm (site 1), 1.20/2.00/2.00 mm (site 2), 0.50/1.50/2.00 mm (site 3), 0.50/2.25/2.50 mm (site 4), $-0.20 /$ 2.50/2.50 mm (site 5), and $-0.70 / 2.75 / 2.50 \mathrm{~mm}$ (site 6) (Fig. $2 \mathrm{~A}$ ). Injection was performed at a constant flow rate of $0.25 \mu \mathrm{l} / \mathrm{min}$ with a microinfusion pump connected to the glass micropipette. After the behavioral testing, mice were anesthetized with sodium pentobarbital, and brain sections were prepared. In situ hybridization analysis of the sections with the $\mathrm{D} 2 \mathrm{R}$ probe confirmed the cell loss in the mutants treated with intrastriatal IT injection.

For intrastriatal administration of acetylethylcholine mustard aziri-

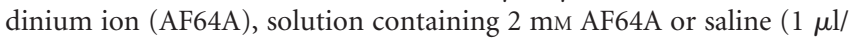
site) was injected through a glass micropipette by using the coordinates (in $\mathrm{mm}$ ): 1.00 anterior, 1.50 lateral, and 2.00 ventral from bregma and dura. Administration was performed with a microinfusion pump. After the behavioral testing, immunohistochemical analysis of brain sections with anti-choline acetyltransferase antibody confirmed the loss of striatal cholinergic interneurons in the animals treated with AF64A administration.

Histology. In situ hybridization was performed as described by Kaneda et al. (1991), with some modifications. Fresh-frozen brain sections (10 $\mu \mathrm{m}$ thick) were fixed in a solution of $4 \%$ paraformaldehyde in $0.1 \mathrm{M}$ 
phosphate buffer (PB), pH 7.4, and treated with $0.1 \mathrm{M}$ triethanolamine, $\mathrm{pH}$ 8.0, containing $0.25 \%$ acetic anhydride. The sections were hybridized with antisense RNA probes labeled by using in vitro transcription with $\left[{ }^{35} \mathrm{~S}\right] \mathrm{dCTP} \alpha \mathrm{S}$ (Perkin-Elmer, Norwalk, CT) or digoxigenin11-UTP (Roche, Basel, Switzerland). The sections were hybridized with radiolabeled probes, washed, and exposed to BAS-MS2040 imaging plates (Fuji Film, Tokyo, Japan). Alternatively, the sections were hybridized with digoxigeninlabeled probes and visualized with a nonradioactive detection system using anti-digoxigenin Fab fragment conjugated to alkaline phosphatase (Roche).

Immunohistochemistry was performed with the ABC method (Lee et al., 1997). Mice were anesthetized with sodium pentobarbital and perfused transcardially with $4 \%$ paraformaldehyde in $0.1 \mathrm{M} \mathrm{PB}$ or $0.2 \%$ picric acid in $0.1 \mathrm{M} \mathrm{PB}$. Free-floating sections ( $30 \mu \mathrm{m}$ thick) were incubated with primary antibodies against synthetic C-terminal nonadecapeptide of preproenkephalin $(1 \mu \mathrm{g} / \mathrm{ml})$ (Lee et al., 1997), synthetic C-terminal pentadecapeptide of preprotachykinin A (1 $\mu \mathrm{g} / \mathrm{ml})$ (Lee et al., 1997), choline acetyltransferase (1:3000 dilution) (Ichikawa et al., 1997), parvalbumin (1:1000 dilution; Sigma, St. Louis, MO), somatostatin (1:100 dilution; Medac, Hamburg, Germany), calretinin (1:1000 dilution; Chemicon, Temecula, CA), tyrosine hydroxylase $(0.4 \mu \mathrm{g} / \mathrm{ml}$; Roche $), \mathrm{DA}$ transporter (1:5000 dilution; Chemicon), c-fos (1:5000 dilution; Santa Cruz Biotechnology, Santa Cruz, CA), and zif268 (1:3000 dilution; Santa Cruz Biotechnology). The sections were incubated with biotinylated secondary antibodies at 1:1000 dilution and visualized with a Vectastain Elite ABC kit (Vector Laboratories, Burlingame, CA).

For cytochrome oxidase (CO) histochemistry (Vila et al., 1996), mice were anesthetized with sodium pentobarbital and perfused transcardially with $4 \%$ paraformaldehyde in $0.1 \mathrm{M}$ PB. Sections (30 $\mu \mathrm{m}$ thick) were incubated in $0.1 \mathrm{M} \mathrm{PB}$ containing $0.5 \mathrm{mg} / \mathrm{ml} 3,3^{\prime}$ diaminobenzidine, $0.15 \mathrm{mg} / \mathrm{ml}$ horse heart cytochrome $c$ (Sigma), and $40 \mathrm{mg} / \mathrm{ml}$ sucrose.

Receptor autoradiography. Radioligand binding was performed as described by Schambra et al. (1994), with slight modifications. For D1 class receptors, fresh-frozen sections $(10 \mu \mathrm{m}$ thick) were incubated in $50 \mathrm{~mm}$ Tris- $\mathrm{HCl}$ buffer, pH 7.4, containing $100 \mathrm{~mm} \mathrm{NaCl}, 5 \mathrm{~mm}$ $\mathrm{KCl}, 2 \mathrm{~mm} \mathrm{CaCl}, 1 \mathrm{~mm} \mathrm{MgCl}$, and $0.4 \mathrm{~nm}\left[{ }^{3} \mathrm{H}\right] \mathrm{SCH} 23390$ (PerkinElmer), and nonspecific binding was determined in the presence of 0.4 $\mu \mathrm{M} \mathrm{SCH} 23390$. For D2 class receptors, the sections were incubated in 50 mu Tris-HCl buffer, pH 7.4, containing $140 \mathrm{~mm} \mathrm{NaCl}$ and $1 \mathrm{~nm}\left[{ }^{3} \mathrm{H}\right] \mathrm{N}$ methylspiperone (NMSP; Perkin-Elmer), and nonspecific binding was determined in the presence of $1 \mu \mathrm{M}$ spiperone. The sections were then washed and exposed to BAS-TR2040 imaging plates (Fuji Film).

Image analysis. Coronal sections through the dorsal striatum, GP, or STN were used for in situ hybridization, immunohistochemistry, CO histochemistry, and receptor autoradiography. The anteroposterior coordinates (in $\mathrm{mm}$ ) from bregma of the sections were between 1.54 and -0.70 for the striatum, between -0.22 and -0.82 for the GP, and between -1.70 and -2.18 for the STN. Fifteen to twenty sections from each animal were used. For each section, a specified square $(0.5 \times 0.5 \mathrm{~mm}$ in the striatum and GP, and $0.1 \times 0.1 \mathrm{~mm}$ in the STN) was selected on the

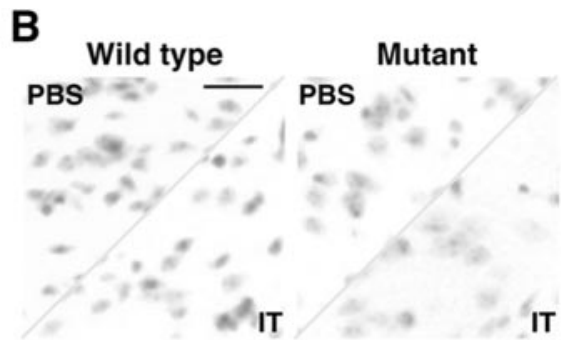

D2R
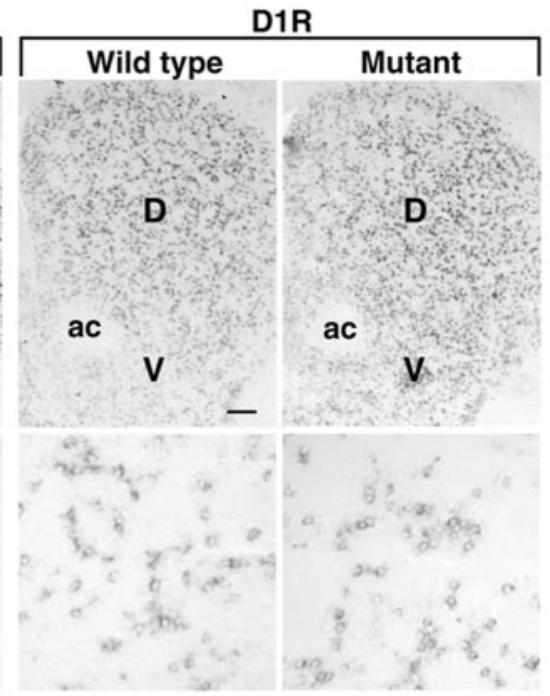

E

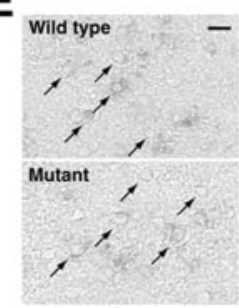

Figure 2. Elimination of the striatal D2R-containing neurons by IT injection. $A$, Schematic illustration of coordinates for the intrastriatal injection. $B$, Cresyl violet staining. Mice were injected unilaterally with IT solution or PBS, and coronal sections $(10 \mu \mathrm{m}$ thick) through the striatum were stained. Scale bar, $25 \mu \mathrm{m}$. C, In situ hybridization analysis of the D2R- and D1R-containing in in the striatum. The sections ( $10 \mu \mathrm{m}$ thick) were hybridized with digoxygenin-labeled riboprobe for a mouse D2R or D1R . 作 $n=4) .{ }^{*} p<0.0001$, significant difference from the IT-injected wild-type mice according to the Tukey HSD test. E, D2R in situ hybridization of the sections through the frontal cortex prepared from mice that received the intrastriatal IT injection. Arrows show the representative cells displaying the hybridization signals. Scale bar, $20 \mu \mathrm{m}$.

corresponding region among individual animals. (The representative positions of the square are shown in supplementary information 1, available at www.jneurosci.org.) The number of stained cells in the square was automatically counted with a computer-assisted imaging program (NIH Image 1.62; National Institutes of Health, Bethesda, MD). The intensity of histochemical signals in the square was measured with the same program. The intensity of radiolabeled signals was measured by using the BAS1000 image processing system (Fuji Film). The average of the values obtained from each animal was calculated.

Neurochemical analysis. Levels of DA and its metabolites DOPAC and homovanillic acid (HVA) were measured by using a high-performance liquid chromatography equipped with an electrochemical detection system (Kobayashi et al., 1994). Tissues were homogenized in 5 volumes of $0.2 \mathrm{~m}$ perchloric acid containing $0.1 \mathrm{M}$ EDTA and the proper concentration of isoproterenol. After centrifugation of the homogenates, the $\mathrm{pH}$ of 
the supernatant was adjusted to 3.0 by adding $1 \mathrm{~m}$ sodium acetate. The mobile phase was $0.1 \mathrm{~m}$ sodium citrate, $0.1 \mathrm{~m}$ citric acid, $0.5 \mathrm{~mm}$ sodium octanesulfonate, $0.15 \mathrm{~mm}$ EDTA, and 12\% methanol, pH 3.5.

Behavioral analysis. For monitoring turning behavior, mice were placed in a spherical bowl ( $25 \mathrm{~cm}$ diameter), and the behavior was recorded with a digital video camera. One rotation was defined as a complete $360^{\circ}$ turn. The number of rotations was counted for every $10 \mathrm{~min}$ period. Turning magnitude was defined as the total number of rotations in a $30 \mathrm{~min}$ test period. Locomotor activity was measured with the movement analyzer using photo beam sensors (Nishii et al., 1998). The number of beam breaks was counted for every $10 \mathrm{~min}$ period (movement score). Locomotor activity was defined as the total number of beam breaks in a 30 min test period.

Statistical analysis. ANOVA, Tukey honestly significant difference (HSD) test, and Student's $t$ test were used with significance set at $p<0.05$ for statistical comparisons. All values were expressed as the mean \pm SEM of the data.

\section{Results}

\section{Generation of mutant mice for targeting the cell types expressing D2R}

To express IL-2R $\alpha$ under the control of the $D 2 R$ gene, we used the knock-in approach, by which the $I L-2 R \alpha$ gene cassette was introduced into exon 2 of the mouse D2R locus with gene targeting in ES cells (Fig. $1 A, B$ ). These ES clones were used to generate chimeric mice, which transmitted the mutation to their offspring. The expression pattern of IL-2R $\alpha$ in mice heterozygous for the knock-in mutation was analyzed by in situ hybridization with a radiolabeled probe (Fig. $1 C$ ). In the mutants, expression of the IL-2R $\alpha$ mRNA was observed in some brain regions including the striatum, the nucleus accumbens, and the ventral midbrain, in which endogenous D2R expression was detected. The data indicate the correct expression of the transgene under the control of the mouse $D 2 R$ gene.

\section{Ablation of D2R-containing neurons in the striatum by IT injection}

Mice heterozygous for the D2R mutation were apparently normal in development and general behavior. In particular, they were normal in striatal structure, DA metabolism, and spontaneous and DA-induced motor behavior (see below). We, thus, used the wild-type and heterozygous mutant littermates (12-16 weeks old). To eliminate the striatal D2R-containing neurons in the basal ganglia circuitry, we unilaterally or bilaterally injected IT solution ( $5 \mathrm{ng} / \mathrm{site}$ ) or PBS into six sites on one side of the dorsal region of the striatum by a stereotaxic approach (Fig. $2 A$ ). In all experiments conducted in this study, the mice were used on day 7 after the injection (day 0 ).

Unilaterally injected mice were subjected to brain sectioning, and the sections through the striatum were stained with cresyl violet (Fig. 2 B). The number of stained cells in the dorsal striatum appeared to be moderately reduced on the IT-injected side in the mutants, although there was no grossly visible damage on the IT-injected side in the wild types or on the PBS-injected sides in either type of mice. The sections through the striatum were analyzed by in situ hybridization with a riboprobe covering the D2R or D1R sequence (Fig. 2C). Evidence of loss of D2R-expressing neurons was found in the striatum of the IT-injected mutants. The cell loss was restricted to the dorsal region of the striatum, and it did not extend to the ventral region. In contrast, D1Rexpressing neurons were spared in the striatum of the injected mutants. The number of neurons containing D2R or D1R in the dorsal striatum was counted (Fig. 2D). The number of D2Rcontaining neurons was not significantly different among the
PBS-injected side of the wild types, PBS-injected side of the mutants, and IT-injected side of the wild types, but it was markedly decreased on the IT-injected side of the mutants $(p<0.0001)$, in which the cell number was only $2.6 \%$ of that on the IT-injected side of the wild types. The number of D1R-containing neurons was statistically indistinguishable among the four different injection sides. In addition, in situ hybridization analysis showed that the cortical neurons expressing D2R appeared intact in the injected mutants (Fig. 2E). These results indicate a selective and efficient ablation of neuronal types containing D2R in the dorsal striatum of the mutants by the IT injection.

The striatopallidal and striatonigral spiny neurons express enkephalin (ENK) and substance P (SP), respectively (Gerfen et al., 1990). Striatal GABAergic interneurons are divided into three categories that express parvalbumin, somatostatin, or calretinin (Kawaguchi et al., 1995). To determine the cell types in the mutant mice affected by the IT injection, we performed immunostaining with antibodies against specific markers for each cell type. For identification of the striatopallidal and striatonigral neurons, we used antibodies for a part of the precursor of ENK (preproenkephalin) or the precursor of SP (preprotachykinin A), respectively. The number of stained cells on the IT-injected side of the striatum was compared between the wild-type and mutant mice (Fig. 3). The number of neurons containing preproenkephalin was significantly reduced in the mutants to $8.9 \%$ of that found in the wild types $(p<0.01)$. However, the number of preprotachykinin A-positive neurons was similar between the two genotypes. In addition, the number of cholinergic interneurons containing choline acetyltransferase was significantly decreased in the mutants to $30 \%$ of that of the wild types $(p<0.05)$, whereas the numbers of the three categories of GABAergic interneurons were unaffected in the mutants. Thus, the IT treatment of the mutants eliminated the majority of the striatopallidal neurons and cholinergic interneurons, although the elimination of cholinergic interneurons was less than that of the striatopallidal neurons.

In situ hybridization analysis of IL-2R $\alpha$ expression showed the expression of the transgene in the ventral midbrain in the mutant mice (Fig. 1C). To examine whether intrastriatal IT injection would damage the nigrostriatal DA pathway, we performed immunohistochemistry with sections through the midbrain or the striatum prepared from unilaterally injected mice. The staining pattern of tyrosine hydroxylase-positive neurons and intensity of their immunoreactive signals in the $\mathrm{SNc}$ exhibited no visible changes on the IT-injected side in the mutants as compared with those for the PBS-injected mutant or the IT- or PBS-injected wild type (Fig. 4A). Also, the distribution of the immunopositive fibers in the striatum on the IT-injected side of the mutants was also unaffected (Fig. $4 B$ ). Staining for DA transporter-positive signals confirmed a normal distribution of the nigrostriatal fibers on the same side (Fig. 4C). Next, we determined levels of DA and its metabolites (DOPAC and HVA) in the striatum of unilaterally injected mice (Fig. 4D). Statistical analysis displayed no significant difference in the levels of DA, DOPAC, or HVA between the two injection sides and two genotypes.

We analyzed specific ligand binding for D2 and D1 class receptors in the dorsal striatum. The sections prepared from unilaterally injected mice were subjected to receptor autoradiography with a D2 class receptor antagonist, $\left[{ }^{3} \mathrm{H}\right] \mathrm{NMSP}$, or a D1 class receptor antagonist, $\left[{ }^{3} \mathrm{H}\right] \mathrm{SCH} 23390$. The influence of IT injection on the number of ligand binding sites was evaluated as the relative ratio of intensity of radiolabeled signals on the ITinjected side to that on the PBS-injected side. The ratio for D2 


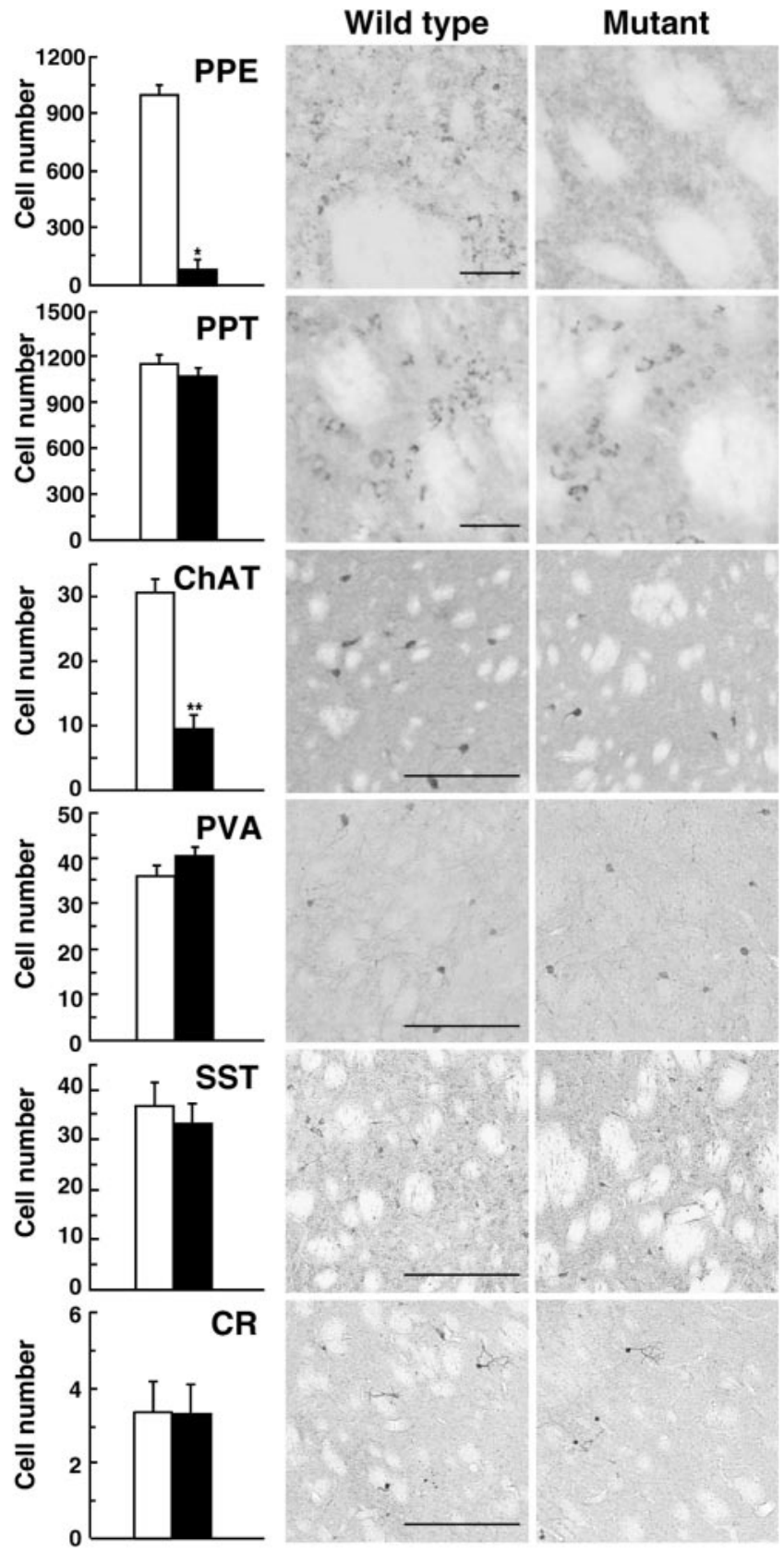

Figure 3. Typing of the neuronal populations affected by IT injection. The sections $(30 \mu \mathrm{m}$ thick) prepared from IT-injected mice were immunohistochemically stained for specific markers of the striatal neuronal populations, including preproenkephalin (PPE), preprotachykinin A (PPT), choline acetyltransferase (ChAT), parvalbumin (PVA), somatostatin (SST), and calretinin (CR). The cell number in the specified areas in the dorsal striatum $(0.5 \times 0.5 \mathrm{~mm})$ was counted. Open column, Wild-type mice $(n=4)$; closed column, mutant mice $(n=4) .{ }^{*} p<0.01$ and ${ }^{* *} p<0.05$, significant differences from the wild-type mice according to Student's $t$ test. Light microscopic images of the representative sections are indicated. Scale bar, $50 \mu \mathrm{m}$.

receptors in the mutants $(0.51 \pm 0.02 ; n=4)$ was reduced to $53 \%$ relative to that in the wild types $(0.97 \pm 0.02 ; n=4 ; p<0.01$, according to Student's $t$ test), whereas the ratio for D1 receptors was similar between the wild types $(0.96 \pm 0.01 ; n=4)$ and the mutants $(0.98 \pm 0.01 ; n=4)$. The IT injection of the mutants led to a marked reduction in the number of D2 binding sites in the striatum but it apparently did not alter the number of D1 binding sites.

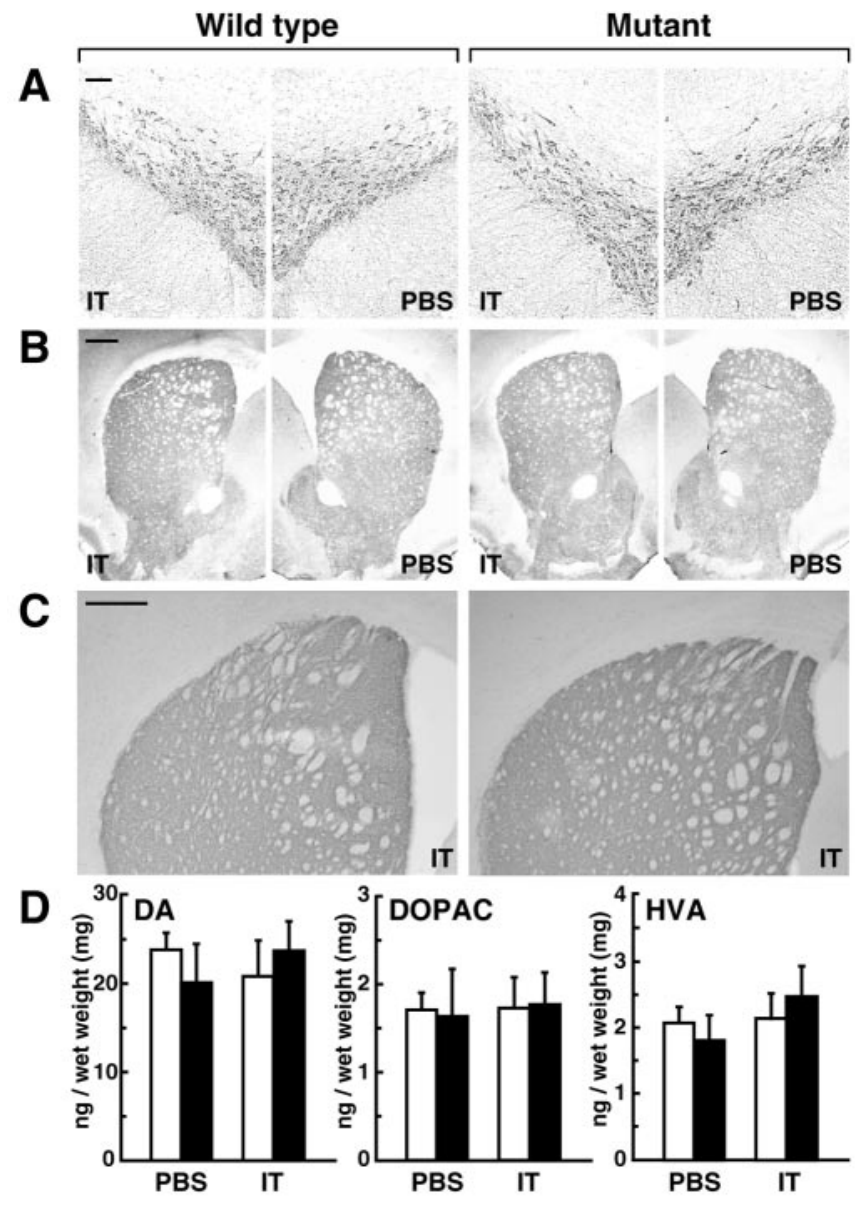

Figure 4. Morphology of the nigrostriatal neurons and metabolism of DA. A-C, Histology of DA neurons. Mice were unilaterally injected with IT solution or PBS, and the sections $(30 \mu \mathrm{m}$ thick) through the midbrain or the striatum were immunohistochemically stained with antibodies for tyrosine hydroxylase (A,B) or DA transporter (C). Scale bar: $A, 100 \mu \mathrm{m} ; B, C, 500 \mu \mathrm{m}$. $D$, Contents of DA, DOPAC, and HVA in the striatum. The tissues were dissected from unilaterally injected mice and analyzed for the levels of DA and its metabolites by using HPLC equipped with an electrochemical detection system. Open column, Wild-type mice $(n=5)$; closed column, mutant mice $(n=5)$.

\section{Ablation of striatal D2R-containing neurons causes abnormal motor behavior}

Asymmetry of basal ganglia output between both hemispheres is known to induce a turning behavior (Pycock, 1980). Unilateral treatment of the basal ganglia nuclei leading to turning contralateral or ipsilateral to the treated side is generally thought to reflect hyperactivity or hypoactivity in movement, respectively, on the treated side. To assess changes in motor behavior caused by ablation of the striatal D2R-containing neurons, we unilaterally injected IT solution into the striatum and then tested spontaneous and drug-induced turning behavior. As shown in Figure 5A, the injected mutants displayed spontaneous turning in the direction contralateral to the injected side. After treatment with methamphetamine (METH; $6.0 \mathrm{mg} / \mathrm{kg}$, s.c.), which stimulates DA release from presynaptic terminals, during the initial 20 min test period, the mutants reversed their turning (ipsilaterally). The ipsilateral turning reached a peak 30-40 min after treatment and then gradually attenuated. In contrast, the injected wild types did not exhibit turning behavior. Turning magnitude defined as the total number of rotations in a 30 min test period during pretreatment or after METH treatment was measured (Fig. 5B). Spontaneous turning magnitude during pretreatment in the contralat- 
A

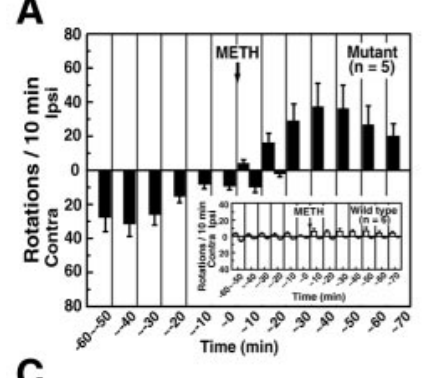

C

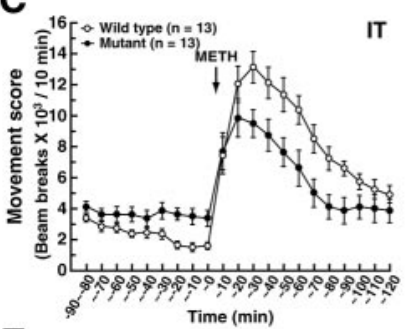

E

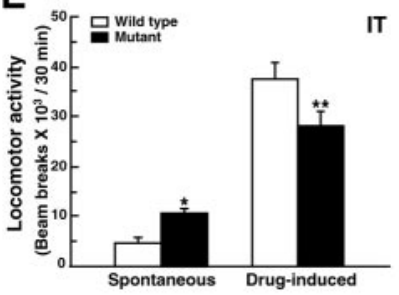

B

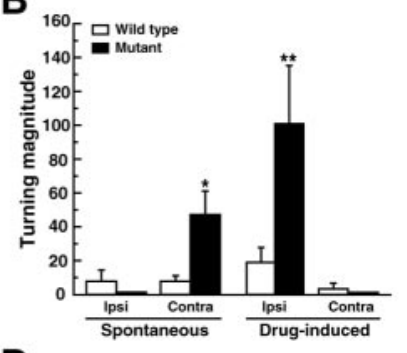

D

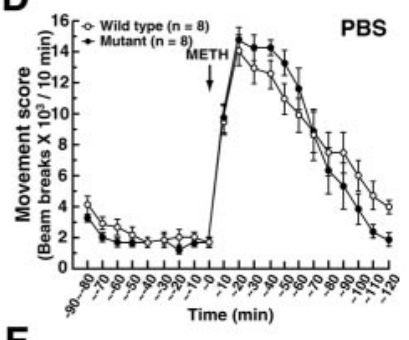

$\mathbf{F}$

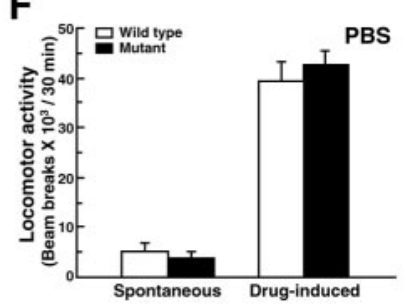

Figure 5. Spontaneous and drug-induced motor behavior. A, Time course of turning behavior of mice unilaterally injected with IT solution. After monitoring of spontaneous rotation for 1 $\mathrm{hr}$, the mice were administered METH $(6.0 \mathrm{mg} / \mathrm{kg}$, s.c.). The number of rotations in the ipsilateral (ipsi) or contralateral (contra) direction was counted for 10 min periods. B, Turning magnitude. The total number of contralateral or ipsilateral rotations in a 30 min test period was calculated to evaluate the spontaneous turning magnitude during the pretreatment $(-40 \mathrm{~min}$ to $-10 \mathrm{~min}$ ) and the drug-induced turning magnitude after METH treatment (20-50 min). ${ }^{*} p<0.001$ versus the wild-type spontaneous turning magnitude; ${ }^{*} p<0.01$ versus the wild-type drug-induced turning magnitude; significant differences according to the Tukey HSD test. C, D, Monitoring of locomotion of mice bilaterally injected with IT solution ( $C$ or PBS (D). After monitoring spontaneous locomotion for $1.5 \mathrm{hr}$, the mice were administered METH (2.0 $\mathrm{mg} / \mathrm{kg}$, s.c.), and the movement score for $10 \mathrm{~min}$ period was measured. $E$, F, Locomotor activity of mice bilaterally injected with IT solution $(E)$ or PBS ( $F$. The total number of the movement score in a 30 min test period was calculated to evaluate spontaneous locomotor activity during the pretreatment $(-30 \mathrm{~min}$ to $0 \mathrm{~min}$ ) and drug-induced locomotor activity after METH treatment $(10-40 \mathrm{~min}) .{ }^{*} p<0.05$ versus the wild-type spontaneous activity; ${ }^{* *} p<0.05$ versus the wild-type drug-induced activity; significant differences according to the Tukey HSD test.

eral direction was significantly increased in the mutants relative to that in the wild types $(p<0.001)$, and the drug-induced turning magnitude in the ipsilateral direction after the treatment was significantly elevated in the mutants $(p<0.01)$. In addition, treatment of apomorphine, which is a nonselective DA agonist, induced the ipsilateral turning in unilaterally IT-injected mutants (supplementary information 2, available at www.jneurosci.org). These results suggest that the unilateral IT injection caused hyperactivity in spontaneous movement on the injected side relative to the intact side (contralateral turning) and that, in response to DA stimulation, it produced an imbalance in motor activation between both sides in an opposite manner to the spontaneous movement (ipsilateral turning).

To further assess the changes in motor behavior derived from ablation of the D2R-containing neurons, we bilaterally injected IT solution and monitored the spontaneous and drug-induced locomotion. As shown in Figure $5 C$, the injected mutants exhibited an increase in spontaneous movement score relative to the

wild types throughout the pretreatment period. After METH treatment $(2.0 \mathrm{mg} / \mathrm{kg}$, s.c. $)$, the movement score was remarkably elevated during the initial $10 \mathrm{~min}$ test period in both kinds of mice. In the wild types, the increase in the score lasted until 20-30 min after treatment, but in the mutants the subsequent increase was moderate and attained a peak at a test period at 10-20 min. Locomotor activity was evaluated as the total number of movement score for $30 \mathrm{~min}$ before or after METH treatment (Fig. 5E). Spontaneous locomotor activity was significantly increased in the mutants relative to that in the wild types $(p<0.05)$, being 2.3fold higher than the wild-type activity. After treatment, druginduced locomotor activity in the wild types exhibited an 8.2-fold increase relative to the wild-type spontaneous activity, whereas the drug-induced locomotor activity in the mutants exhibited a 2.7-fold increase relative to the mutant spontaneous activity, but it was significantly lower than the corresponding value of the wild types $(75 \%$; $p<0.01)$. Mice of both genotypes that received a bilateral sham operation with PBS displayed similar spontaneous and drug-induced locomotion (Fig. 5D,F). Bilateral elimination of D2R-expressing neurons resulted in hyperactivity in spontaneous locomotion and impaired motor activation in response to DA stimulation. These results agree with the data obtained from the turning behavior of the unilaterally IT-injected mutants, particularly suggesting that in these mutants the METH-induced movement on the intact side became more hyperactive relative to that on the injected side.

\section{Ablation of D2R-containing neurons shifts gene expression in basal ganglia circuitry}

An increase or decrease in the activity of striatonigral neurons is known to upregulate or downregulate, respectively, the level of mRNA encoding SP (Gerfen et al., 1990). The level of mRNA encoding an isoform of GAD (GAD67) is used to analyze changes in GABAergic activity in the GP neurons (Murer et al., 2000; Bacci et al., 2002). In addition, the activity of CO is an index of the metabolic activity of the STN neurons (Vila et al., 1996). To characterize changes in the basal ganglia circuitry in our ITinjected mutants, we investigated the expression levels of those neuronal markers. The sections prepared from unilaterally injected mice were subjected to in situ hybridization for SP mRNA in the dorsal striatum or for GAD67 mRNA in the GP and to histochemistry for CO activity in the STN. The effect of the IT injection on the expression levels was evaluated as the ratio of intensity on the IT-injected side relative to that on the PBSinjected side. The representative results obtained from analysis of expression levels on the IT-injected side are shown in Figure 6. The ratio of SP mRNA levels was not statistically distinguishable between the wild types $(0.98 \pm 0.02 ; n=7)$ and the mutants $(1.02 \pm 0.04 ; n=6)$, whereas the ratio of GAD67 mRNA levels in the mutants $(1.17 \pm 0.03 ; n=6)$ was 1.2 -fold higher than that in the wild types $(0.97 \pm 0.02 ; n=7 ; p<0.01$, according to Student's $t$ test $)$. The ratio of CO activity in the mutants $(0.93 \pm 0.01$; $n=5$ ) was mildly but significantly decreased to $93 \%$ of the wild type value $(1.00 \pm 0.01 ; n=6 ; p<0.01)$. These data suggest that the cell elimination modulated the activity of the GP and STN neurons, while preserving the activity of the striatonigral neurons at the normal level.

Administration of METH induces the expression of the immediate-early gene (IEG) c-fos in the striatum, GP, and STN (Graybiel et al., 1990; Cenci et al., 1992; Ruskin and Marshall, 1995). In the striatum, c-fos expression is specifically induced in the striatonigral spiny neurons (Berretta et al., 1992; Cenci et al., 1992). To characterize the DA-dependent response of the basal 


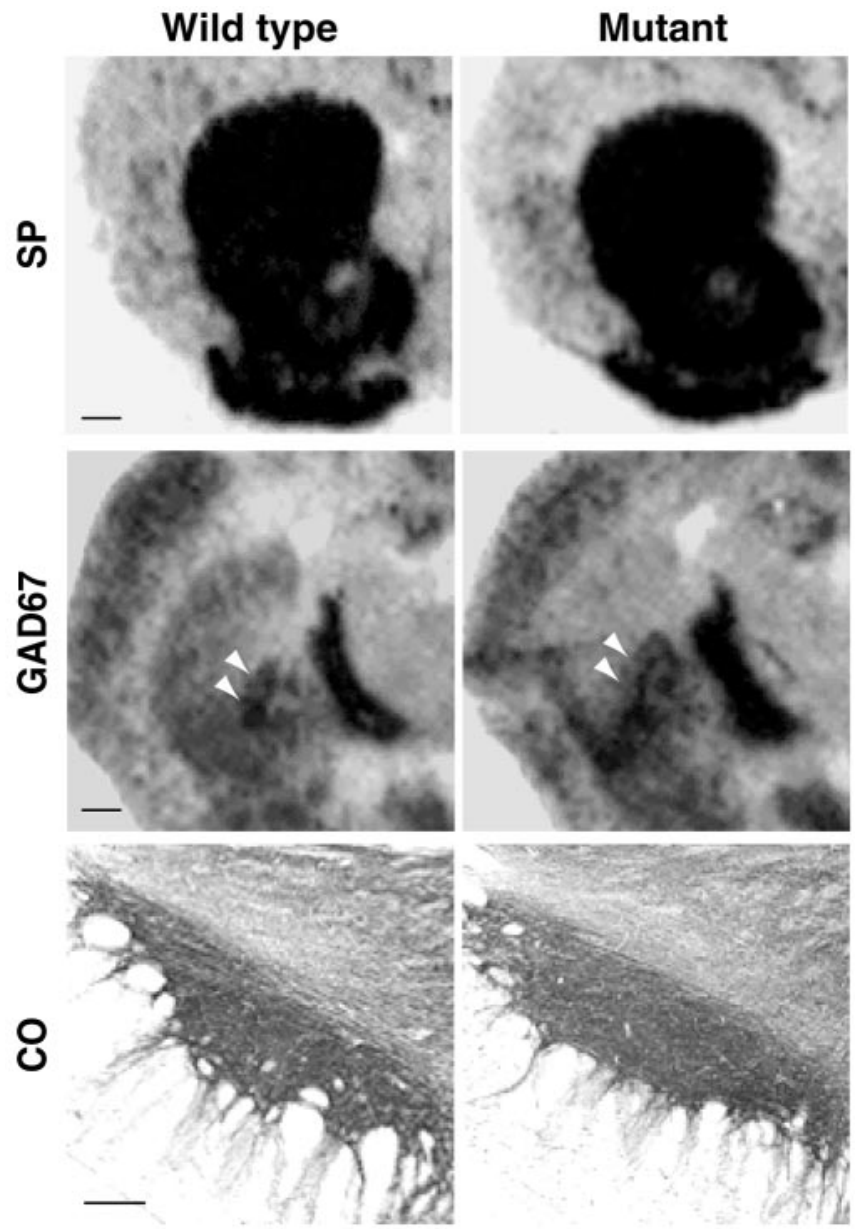

Figure 6. Expression of gene markers correlated with neuronal activity. Coronal sections (10 $\mu \mathrm{m}$ thick) through the striatum and GP were analyzed by in situ hybridization for SP mRNA and for GAD67 mRNA, respectively. The sections ( $30 \mu \mathrm{m}$ thick) through the STN were analyzed by histochemistry for $\mathrm{CO}$ activity. Representative autoradiographic and histochemical images of the IT-injected side are shown. Arrowheads show the positions of the GP. Scale bars: SP and GAD67, $500 \mu \mathrm{m} ; \mathrm{CO}, 100 \mu \mathrm{m}$.

ganglia circuitry in the injected mutants, we explored c-fos expression in the brain after METH treatment. The effect of IT injection in the gene expression was evaluated as the relative ratio of the number of c-fos-positive cells on the IT-injected side to that on the PBS-injected side. The representative data of c-fos immunohistochemistry on the IT-injected side are shown in Figure $7 \mathrm{~A}$. In the striatum, the ratio of the cell number was significantly attenuated in the mutants $(0.81 \pm 0.03, n=5)$ to $77 \%$ of the wild-type value ( $1.05 \pm 0.04 ; n=5 ; p<0.01$; Student's $t$ test $)$. In contrast, the ratio in the GP was not statistically different between the wild types $(1.04 \pm 0.03 ; n=5)$ and the mutants $(0.92 \pm 0.05$; $n=5)$. The ratio in the STN also resembled the wild types (1.05 \pm $0.08 ; n=5)$ and the mutants $(1.05 \pm 0.13 ; n=5)$. These data suggest that the cell elimination attenuated the activation of the striatonigral neurons in response to METH stimulation, but it apparently unaffected the activation of the GP and STN neurons.

METH stimulation also induces the expression of another IEG zif268 in the striatum (Nguyen et al., 1992; Gerfen et al., 1995). To ascertain the effect of the cell ablation in the METHinduced response of the striatonigral neurons, we examined the expression of zif268 in the striatum after METH treatment (Fig. $7 B$ ). The relative ratio of the number of zif268-positive cells on the IT-injected side to that on the PBS-injected side was reduced
A

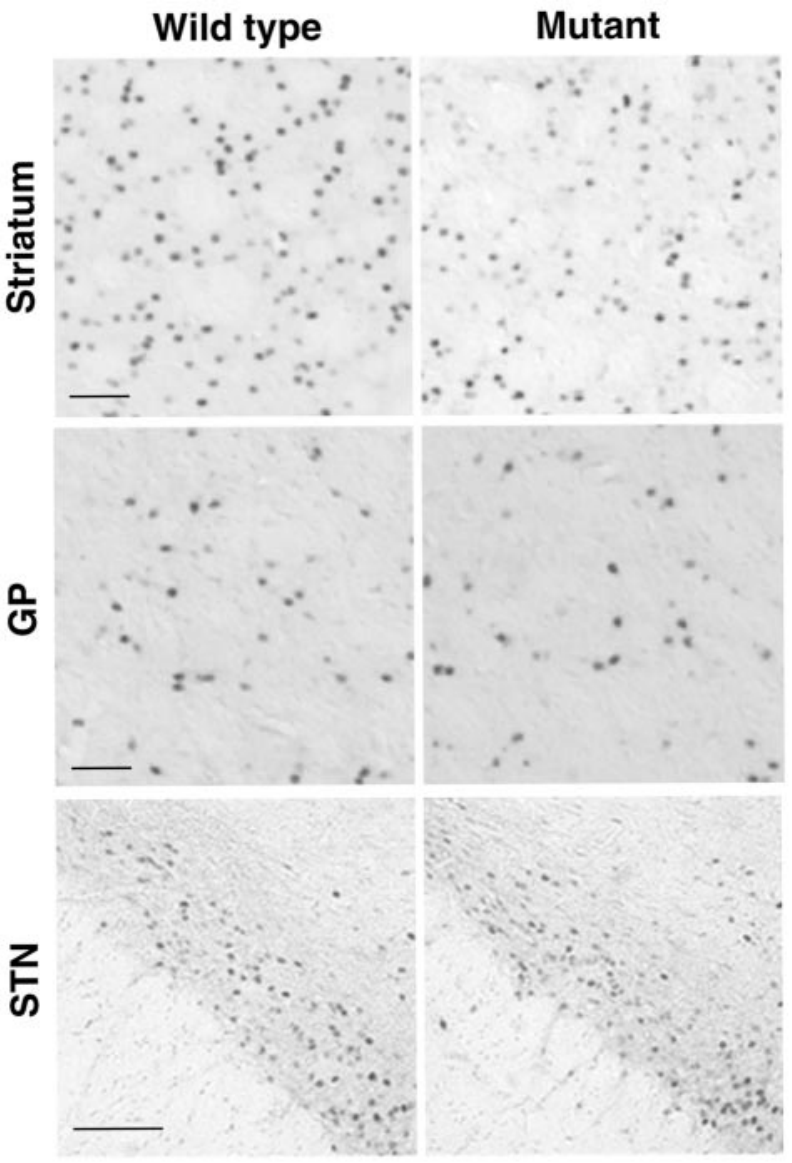

B

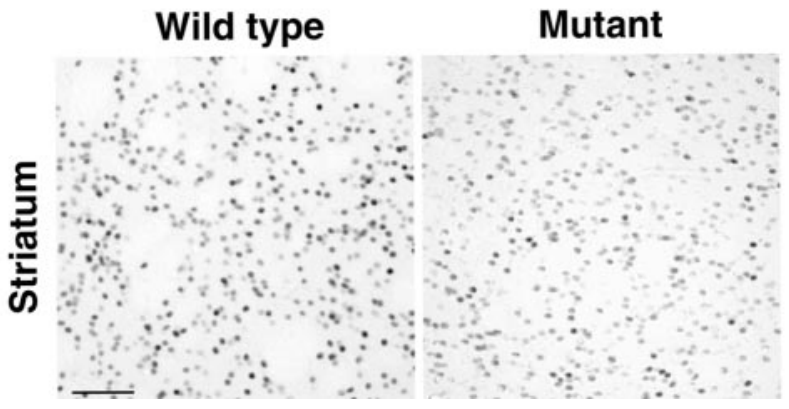

Figure 7. Induction of IEGs in response to DA stimulation. A, c-Fos induction. Unilaterally injected mice were administered METH $(6.0 \mathrm{mg} / \mathrm{kg}$, s.c.), and $1 \mathrm{hr}$ after the administration, brain sections were taken. The sections (30 $\mu \mathrm{m}$ thick) through the striatum, GP, or STN were immunostained with anti-c-fos antibody. Light microscopic images of the IT-injected side are indicated. Scale bar, $100 \mu \mathrm{m}$. B, Zif268 induction. The sections through the striatum were immunostained with anti-zif268 antibody. Light microscopic images of the IT-injected side are indicated. Scale bar, $100 \mu \mathrm{m}$.

in the mutants $(0.75 \pm 0.04 ; n=6)$ to $76 \%$ of the wild-type value $(0.98 \pm 0.02 ; n=6 ; p<0.01$; Student's $t$ test $)$. The results agree with the data obtained from analysis of c-fos induction showing that the cell elimination attenuated upregulation of the striatonigral activity in response to drug stimulation.

\section{Influence of chemical lesion of cholinergic interneurons in the behavior and gene expression in the circuitry}

$\mathrm{ACh}$ is considered to function to suppress locomotor activity through antagonizing DA actions via muscarinic receptor subtypes by inhibiting the striatonigral neurons and by stimulating the striatopallidal neurons (Di Chiara et al., 1994; Wang and 
A

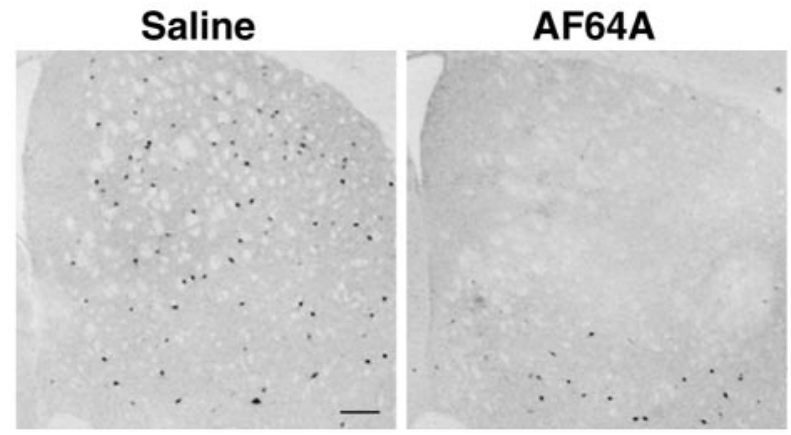

B

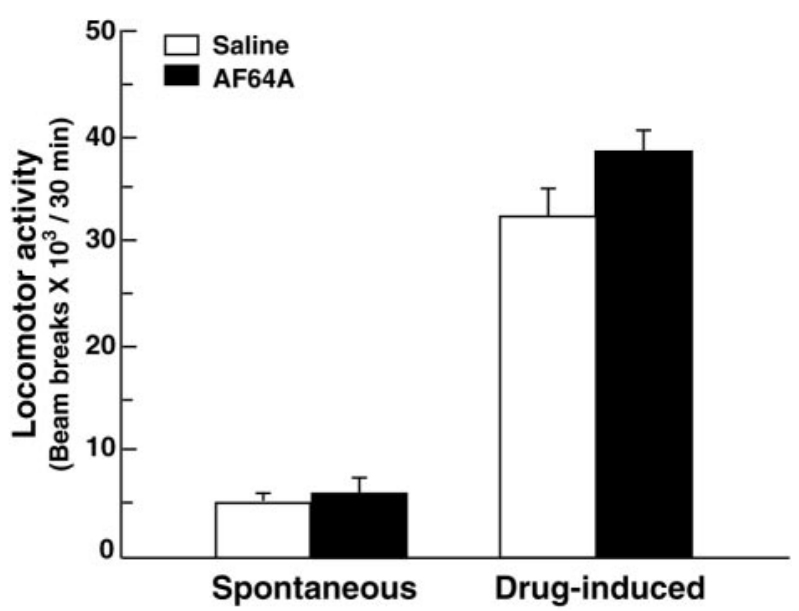

C
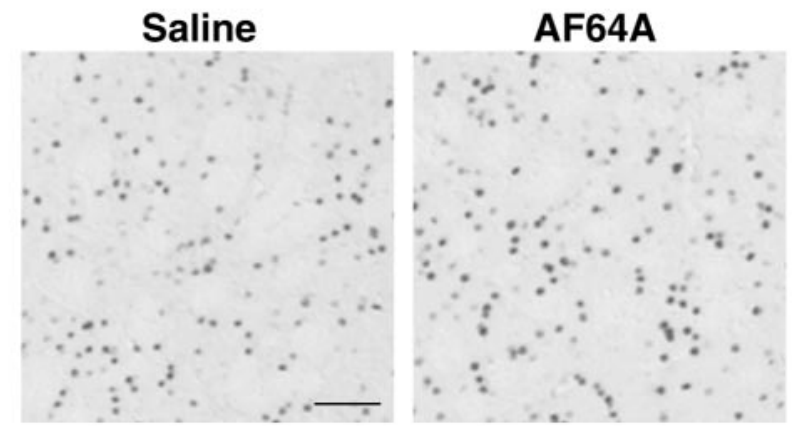

Figure 8. Chemical lesion of striatal cholinergic interneurons. $A$, Immunohistochemistry. Mice were unilaterally administered AF64A or saline into the striatum, and brain sections were taken. The sections ( $30 \mu \mathrm{m}$ thick) through the striatum were immunostained with anti-choline acetyltransferase antibody. Scale bar, $200 \mu \mathrm{m}$. B, Locomotor activity. Mice $(n=6)$ were bilaterally treated with AF64A or saline and used for measurement of spontaneous locomotor activity during the pretreatment and drug-induced locomotor activity after METH administration. C, c-Fos induction. Unilaterally injected mice were administered METH and used for brain sectioning. The sections (30 $\mu \mathrm{m}$ thick) through the striatum were stained with anti-c-fos antibody. Scale bar, $100 \mu \mathrm{m}$.

McGinty, 1997; Kaneko et al., 2000). To evaluate the influence of ablation of striatal cholinergic interneurons in spontaneous and $\mathrm{METH}$-induced motor behavior, we administered intrastriatally AF64A, which is a selective cholinergic neurotoxin (Fisher et al., 1982). Immunohistochemical analysis with anti-choline acetyltransferase antibody indicated the loss of the majority of cholinergic interneurons in the AF64A-treated group (Fig. $8 \mathrm{~A}$ ). The number of the positive cells in the AF64A-treated group was 34\% relative to that of the saline-treated group $(n=4 ; p<0.01$, according to Student's $t$ test). Mice bilaterally administered
AF64A or saline were tested for locomotor activity (Fig. 8 B). Spontaneous locomotor activity was indistinguishable between the AF64A- and saline-treated groups. Drug-induced locomotor activity exhibited a modest increase in the AF64A-treated group, being 1.2-fold higher than the saline-treated group. In addition, we examined c-fos induction in the striatum of unilaterally lesioned mice after METH treatment (Fig. 8C). The number of c-fos-positive cells in the AF64A-treated side was $117 \%$ relative to that in the saline-treated side $(n=6 ; p<0.05$, according to Student's $t$ test). These results indicate that lesion of striatal cholinergic interneurons acted to enhance moderately METHinduced motor behavior with no apparent influence in spontaneous motor behavior, consistent with previous studies that show the role of cholinergic interneurons in suppression of DAinduced motor behavior (Di Chiara et al., 1994; Wang and McGinty, 1997; Kaneko et al., 2000).

\section{Discussion}

In the present study, we achieved conditional ablation of striatal neuronal types containing D2R by using IMCT technology. The mutant mice were generated that express human IL-2R $\alpha$ under the control of the $D 2 R$ gene. Intrastriatal IT injection of the mutants resulted in elimination of the majority of the striatopallidal medium spiny neurons and cholinergic interneurons. The elimination of these neurons caused hyperactivity of spontaneous movement and reduced motor activation in response to DA stimulation. The elimination also induced upregulation of GAD67 mRNA expression in the GP neurons and downregulation of CO activity in the STN neurons, whereas it attenuated DA-induced IEG expression in the striatonigral neurons. In addition, chemical lesion of cholinergic interneurons did not alter spontaneous movement but caused a moderate enhancement in DA-induced motor activation. This enhancement of the behavior was accompanied by an increase in the IEG expression in the striatonigral neurons.

Previous histological studies reported a selective localization of D1R in the striatonigral neurons and D2R in the striatopallidal neurons (Gerfen et al., 1990; Hersch et al., 1995; Yung et al., 1995). However, other data presented colocalization of these subtypes in some single spiny neurons (Lester et al., 1993; Surmeier et al., 1996). In the present study, IMCT of striatal D2Rcontaining neurons eliminated the majority of striatopallidal neurons while having no influence on the number of striatonigral neurons or D1R-containing neurons. Our results agree with the previous studies reporting that the D1R and D2R subtypes are separately expressed in the different subpopulations of spiny neurons (Gerfen et al., 1990; Hersch et al., 1995; Yung et al., 1995). Among various types of striatal interneurons, our IMCT reduced the number of cholinergic interneurons, and the extent of the cell loss was $70 \%$. The data support a previous study showing that a subpopulation of striatal cholinergic interneurons expresses the D2R subtype (Aubry et al., 1993). In addition, our intrastriatal IT injection of the mutants produced no visible damage in the morphology of the nigrostriatal neurons or in the DA metabolism despite the abundant expression of IL-2R $\alpha$, indicating that DA neurons are resistant to IT molecules infused into their synaptic terminal regions. This resistance may be because of inefficiency of the receptor-mediated endocytosis from the synaptic terminals or that of retrograde axonal transport of IT molecules. Alternatively, IL-2R $\alpha$ protein expressed in DA neurons may not be able to efficiently translocate to the terminal regions. Furthermore, IT injection of the mutants led to the reduction of approximately half the number of D2 binding sites in the stria- 
tum. The extent of the reduction is a consequence of ablation of the striatopallidal neurons and cholinergic interneurons containing the D2R subtype. The remaining binding sites in the injected mutants may be derived from other D2 class receptor subtypes expressed in the intact striatal neurons or from the autoreceptor localized in the synaptic terminals of the nigrostriatal DA neurons.

In the standard model of the basal ganglia circuitry, the roles of the direct and indirect pathways have been considered to be implicated in activation and suppression of motor behavior, respectively (Alexander and Crutcher, 1990; DeLong, 1990; Gerfen and Wilson, 1996). At the striatal level, DA appears to facilitate the striatonigral neurons through the D1R subtype and to inhibit the striatopallidal neurons through the D2R subtype (Gerfen and Wilson, 1996). Our ITinjected mutant mice displayed the hyperactivity in spontaneous movement, whereas chemical lesion of striatal cholinergic interneurons showed no apparent influence in the movement. These behavioral data suggest that the spontaneous hyperactivity in the injected mutants is predominantly attributable to ablation of the striatopallidal neurons. The spontaneous hyperactivity in the ITinjected mutants was accompanied by the increase in the GAD67 mRNA level in the GP neurons and the decrease in CO activity in the STN neurons, with no apparent change in the SP mRNA level in the striatonigral neurons. These data suggest that the behavior is derived from modulation of neuronal activity in the indirect pathway. In particular, the elimination of the striatopallidal pathway may cause upregulation of the GP activity and downregulation of the STN activity, which reduce the net activity of basal ganglia output, thus leading to hyperactivity (Fig. 9A). Our data suggest that the striatopallidal neurons normally suppress spontaneous movement through inhibition of the GP neurons, in keeping with the role of the indirect pathway in the standard model of the circuitry.

In contrast, the IT-injected mutant mice displayed a reduction in METH-induced motor behavior, whereas chemical lesion of cholinergic interneurons caused a modest increase in METHinduced behavior. The behavioral data suggest that the reduced motor behavior in the IT-injected mutants is mainly derived from ablation of the striatopallidal neurons, and that a greater decrease in locomotion because of the striatopallidal ablation may mask the opposite effect of the loss of cholinergic interneurons. In addition, the IT injection of the mutants attenuated METH-induced IEG expression in the striatonigral neurons, while retaining a normal level of the IEG expression in the GP and STN. Lesion of cholinergic interneurons slightly increased the IEG expression in the striatonigral neurons. The comparison of IEG expression levels in the striatonigral neurons between ITinjected mutant and chemically lesioned mice suggests that the attenuated IEG expression in the injected mutants is linked mostly to the ablation of the striatopallidal neurons. Taken together, these data suggest that elimination of the striatopallidal neurons reduces DA-induced motor activation at least in part through the insufficient activation of the striatonigral neurons, which inhibits a normal suppression of the basal ganglia output (Fig. 9B,C). The striatopallidal neurons appear to be involved in full expression of DA-induced behavior not only through the disinhibition of the GP neurons but also through the facilitation of the striatonigral pathway, although the precise mechanism by which changes in the activity of the striatopallidal neurons affect the striatonigral pathway is not clear.

One possible mechanism for the regulation of the striatonigral neurons in response to DA transmission through the striatopallidal neurons is modulation of inhibitory transmission via local axon collaterals of medium spiny neurons within the striatal circuitry. Spiny neurons extend the axon collaterals that make synaptic contact with other striatal cells (Wilson and Groves, 1980). Although a previous study failed to detect mutual electrophysiological responses between spiny neurons (Jaeger et al., 1994), recent reports showed that these neurons are interconnected by GABAergic synaptic transmission (Czubayko and Plenz, 2002; Tunstall et al., 2002). Spiny neurons also receive synaptic inputs from some types of GABAergic interneurons (Kawaguchi, 1993; Koós and Tepper, 1999; Kubota and Kawaguchi, 2000). These observations suggest that D2R-mediated inhibition of the striatopallidal neurons may subserve D1R-mediated facilitation of the striatonigral neurons through axonal interactions between spiny neurons or through the interneuronal network. The D2Rmediated inhibition may need to be temporally coupled with the D1R-mediated facilitation to express an adequate response of the striatonigral neurons, as observed in many DA actions requiring synergistic effects between D1 class and D2 class receptors (LaHoste et al., 1993; Gerfen et al., 1995). Another possible mechanism may involve the function of ENK that inhibits the striatonigral activity. ENK is reported to depress D1 class receptormediated CAMP signal transduction in the striatal slices (Schoffelmeer et al., 1993; Lindskog et al., 1999). Also, the mRNA encoding $\mu$-opioid receptors appears to be localized in the majority of striatonigral neurons in the striosomal patch compartments (Guttenberg et al., 1996). These data suggest that DAdependent reduction in ENK levels may be implicated in facilitation of the striatonigral activity. The detailed cellular mechanism that controls the striatonigral activity in response to DA transmission through the striatopallidal neurons remains to be determined.

Finally, IMCT technology enabled us to perform functional analysis of the basal ganglia circuitry by ablating specific neuronal types in the striatum. Our results provide evidence that the striatopallidal medium spiny neurons play a key role in dual regulation of motor behavior depending on the state of DA 
transmission through coordination of the neural circuitry. In particular, the impairment of DA-induced motor activation observed in the IT-injected mutants does not simply result from removal of the suppression of motor behavior by the indirect pathway according to the standard model of the basal ganglia circuitry. The data suggest the presence of an additional mechanism that facilitates the motor behavior in response to DA stimulation through the striatopallidal neurons. Understanding molecular and cellular mechanisms for the neural circuit coordination should help us to elucidate the physiological basis of various psychomotor functions mediated by the basal ganglia as well as the pathological conditions of the disorders associated with disturbance in the basal ganglia.

\section{References}

Alexander GE, Crutcher MD (1990) Functional architecture of basal ganglia circuits: neural substrates of parallel processing. Trends Neurosci 13:266-271.

Aubry J-M, Schulz M-F, Pagliusi S, Schultz P, Kiss JZ (1993) Coexpression of dopamine $\mathrm{D}_{2}$ and substance $\mathrm{P}$ (neurokinin-1) receptor messenger RNAs by a subpopulation of cholinergic neurons in the rat striatum. Neuroscience 53:417-424.

Bacci J-J, Goff LK-L, Salin P (2002) Effects of intralaminar thalamic nuclei lesion on glutamic acid decarboxylase (GAD65 and GAD67) and cytochrome oxidase subunit I mRNA expression in the basal ganglia of the rat. Eur J Neurosci 15:1918-1928.

Bergman H, Feingold A, Nini A, Raz A, Slovin H, Abeles M, Vaadia E (1998) Physiological aspects of information processing in the basal ganglia of normal and parkinsonian primates. Trends Neurosci 21:32-38.

Berretta S, Robertson HA, Graybiel AM (1992) Dopamine and glutamate agonists stimulate neuron-specific expression of Fos-like protein in the striatum. J Neurophysiol 68:767-777.

Bevan MD, Magill PJ, Terman D, Bolam JP, Wilson CJ (2002) Move to the rhythm: oscillations in the subthalamic nucleus-external globus pallidus network. Trends Neurosci 25:525-531.

Cenci MA, Kalén P, Mandel RJ, Wictorin K, Björklund A (1992) Dopaminergic transplants normalize amphetamine- and apomorphine-induced Fos expression in the 6-hydroxydopamine-lesioned striatum. Neuroscience 46:943-957.

Civelli O, Bunzow JR, Grandy DK (1993) Molecular diversity of the dopamine receptors. Annu Rev Pharmacol Toxicol 33:281-307.

Czubayko U, Plenz D (2002) Fast synaptic transmission between striatal spiny projection neurons. Proc Natl Acad Sci USA 99:15764-15769.

DeLong MR (1990) Primate models of movement disorders of basal ganglia origin. Trends Neurosci 13:281-285.

Di Chiara G, Morelli M, Consolo S (1994) Modulatory functions of neurotransmitters in the striatum: ACh/dopamine/NMDA interactions. Trends Neurosci 17:228-233.

Fisher A, Mantione CR, Abraham DJ, Hanin I (1982) Long-term central cholinergic hypofunction induced in mice by ethylcholine azirizium ion (AF64A) in vivo. J Pharmacol Exp Ther 222:140-145.

Gerfen CR, Wilson CJ (1996) The basal ganglia. In: Handbook of chemical anatomy, Vol 12 (Swanson LW, Björklund A, Hökfelt T, eds), pp 37-468. Amsterdam: Elsevier.

Gerfen CR, Engber TM, Mahan LC, Susei Z, Chase TN, Monsma Jr FJ, Sibley DR (1990) $D_{1}$ and $D_{2}$ dopamine receptor-regulated gene expression of striatonigral and striatopallidal neurons. Science 250:1429-1432.

Gerfen CR, Keefe KA, Gauda EB (1995) D1 and D2 dopamine receptor function in the striatum: coactivation of D1- and D2-dopamine receptors on separate populations of neurons results in potentiated immediate early gene response in D1-containing neurons. J Neurosci 15:8167-8176.

Graybiel AM (1995) Building action repertoires: memory and learning functions of the basal ganglia. Curr Biol 5:733-741.

Graybiel AM, Moratalla R, Robertson HA (1990) Amphetamine and cocaine induce drug-specific activation of the c-fos gene in striosome-matrix compartments and limbic subdivisions of the striatum. Proc Natl Acad Sci USA 87:6912-6916.

Guttenberg ND, Klop H, Minami M, Satoh M, Voorn P (1996) Co- localization of $\mu$ opioid receptor is greater with dynorphin than enkephalin in rat striatum. NeuroReport 7:2119-2124.

Hersch SM, Ciliax BJ, Gutekunst C-A, Rees HD, Heilman CJ, Yung KKL, Bolam JP, Ince E, Yi H, Levey AI (1995) Electron microscopic analysis of D1 and D2 dopamine receptor proteins in the dorsal striatum and their synaptic relationships with motor corticostriatal afferents. J Neurosci 15:5222-5237.

Ichikawa T, Ajiki K, Matsuura J, Misawa H (1997) Localization of two cholinergic markers, choline acetyltransferase and vesicular acetylcholine transporter in the central nervous system of the rat: in situ hybridization histochemistry and immunohistochemistry. J Chem Neuroanat 13:23-39.

Jaeger D, Kita H, Wilson CJ (1994) Surround inhibition among projection neurons is weak or nonexistent in the rat neostriatum. J Neurophysiol 72:2555-2558.

Kaneda N, Sasaoka T, Kobayashi K, Kiuchi K, Nagatsu I, Kurosawa Y, Fujita K, Yokoyama M, Nomura T, Katsuki M, Nagatsu T (1991) Tissuespecific and high-level expression of the human tyrosine hydroxylase gene in transgenic mice. Neuron 6:583-594.

Kaneko S, Hikida T, Watanabe D, Ichinose H, Nagatsu T, Kreitman RJ, Pastan I, Nakanishi S (2000) Synaptic integration mediated by striatal cholinergic interneurons in basal ganglia function. Science 289:633-637.

Kawaguchi Y (1993) Physiological, morphological, and histochemical characterization of three classes of interneurons in rat neostriatum. J Neurosci 13:4908-4923.

Kawaguchi Y, Wilson CJ, Augood SJ, Emson PC (1995) Striatal interneurones: chemical, physiological and morphological characterization. Trends Neurosci 18:527-535.

Kobayashi K, Morita S, Mizuguchi T, Sawada H, Yamada K, Nagatsu I, Fujita K, Nagatsu T (1994) Functional and high level expression of human dopamine $\beta$-hydroxylase in transgenic mice. J Biol Chem 269:29725-29731.

Kobayashi K, Morita S, Sawada H, Mizuguchi T, Yamada K, Nagatsu I, Fujita K, Kreitman RJ, Pastan I, Nagatsu T (1995a) Immunotoxin-mediated conditional disruption of specific neurons in transgenic mice. Proc Natl Acad Sci USA 92:1132-1136.

Kobayashi K, Morita S, Sawada H, Mizuguchi T, Yamada K, Nagatsu I, Hata T, Watanabe Y, Fujita K, Nagatsu T (1995b) Targeted disruption of the tyrosine hydroxylase locus results in severe catecholamine depletion and perinatal lethality in mice. J Biol Chem 270:27235-27243.

Koós T, Tepper JM (1999) Inhibitory control of neostriatal projection neurons by GABAergic interneurons. Nat Neurosci 2:467-472.

Kreitman RJ, Bailon P, Chaudhary VK, FitzGerald DJ, Pastan I (1994) Recombinant immunotoxins containing anti-Tac $(\mathrm{Fv})$ and derivertives of Pseudomonas exotoxin produce complete regression in mice of an interleukin-2 receptor-bearing human carcinoma. Blood 83:426-434.

Kubota Y, Kawaguchi Y (2000) Dependence of GABAergic synaptic areas on the interneuron type and target size. J Neurosci 20:375-386.

LaHoste GJ, Yu J, Marshall JF (1993) Striatal Fos expression is indicative of dopamine D1/D2 synergism and receptor supersensitivity. Proc Natl Acad Sci USA 90:7451-7455.

Lee T, Kaneko T, Taki K, Mizuno N (1997) Preprodynorphin-, preproenkephalin-, and preprotachykinin-expressing neurons in the rat neostriatum: an analysis by immunocytochemistry and retrograde tracing. J Comp Neurol 386:229-244.

Lester J, Fink S, Aronin N, DiFiglia M (1993) Colocalization of $D_{1}$ and $D_{2}$ dopamine receptor mRNAs in striatal neurons. Brain Res 621:106-110.

Lindskog M, Svenningsson P, Fredholm B, Greengard P, Fisone G (1999) $\mu$ and $\delta$-Opioid receptor agonists inhibit DARPP-32 phosphorylation in distinct populations of striatal projection neurons. Eur J Neurosci 11:2182-2186.

Murer MG, Dziewczapolski G, Salin P, Vila M, Tseng KY, Ruberg M, Rubinstein M, Kelly MA, Grandy DK, Low MJ, Hirsch E, Raisman-Vozari R, Gershanik O (2000) The indirect basal ganglia pathway in dopamine $\mathrm{D}_{2}$ receptor-deficient mice. Neuroscience 99:643-650.

Nambu A, Tokuno H, Takada M (2002) Functional significance of the cortico-subthalamo-pallidal 'hyperdirect' pathway. Neurosci Res 43:111-117.

Nguyen TV, Kosofsky BE, Birnbaum R, Cohen BM, Hyman SE (1992) Differential expression of c-Fos and Zif268 in rat striatum after haloperidol, clozapine, and amphetamine. Proc Natl Acad Sci USA 89:4270-4274. 
Nicola SM, Surmeier DJ, Malenka RC (2000) Dopaminergic modulation of neuronal excitability in the striatum and nucleus accumbens. Annu Rev Neurosci 23:185-215.

Nishii K, Matsushita N, Sawada H, Sano H, Noda Y, Mamiya T, Nabeshima T, Nagatsu I, Hata T, Kiuchi K, Yoshizato H, Nakashima K, Nagatsu T, Kobayashi K (1998) Motor and learning dysfunction during postnatal development in mice defective in dopamine neuronal transmission. J Neurosci Res 54:450-464.

Paxinos G, Franklin KBJ (2001) The mouse brain in stereotaxic coordinates, Ed 2. San Diego: Academic.

Pycock CJ (1980) Turning behavior in animals. Neuroscience 5:461-514.

Ruskin DN, Marshall JF (1995) D1 dopamine receptors influence Fos immunoreactivity in the globus pallidus and subthalamic nucleus of intact and nigrostriatal-lesioned rats. Brain Res 703:156-164.

Schambra UB, Duncan GE, Breese GR, Fornaretto MG, Caron MG, Fremeau Jr RT (1994) Ontogeny of D1A and D2A dopamine receptor subtypes in rat brain using in situ hybridization and receptor binding. Neuroscience 62:65-85.

Schoffelmeer ANM, De Vries TJ, Hogenboom F, Mulder AH (1993) Muand delta-opioid receptors inhibitorily linked to dopamine-sensitive adenylate cyclase in rat striatum display a selectivity profile toward endogenous opioid peptides different from that of presynaptic mu, delta and kappa receptors. J Pharmacol Exp Ther 267:205-210.

Schultz W, Dayan P, Montague PR (1997) A neural substrate of prediction and reward. Science 275:1593-1599.

Surmeier DJ, Song W-J, Yan Z (1996) Coordinated expression of dopamine receptors in neostriatal medium spiny neurons. J Neurosci 16:6579-6591.

Tunstall MJ, Oorschot DE, Kean A, Wickens JR (2002) Inhibitory interactions between spiny projection neurons in the rat striatum. J Neurophysiol 88:1263-1269.

Vila M, Levy R, Herrero M-T, Faucheux B, Obeso JA, Agid Y, Hirsch EC (1996) Metabolic activity of the basal ganglia in Parkinsonian syndromes in human and non-human primates: a cytochrome oxidase histochemistry study. Neuroscience 71:903-912.

Wang JQ, McGinty JF (1997) Intrastriatal injection of a muscarinic receptor agonist and antagonist regulates striatal neuropeptide mRNA expression in normal and amphetamine-treated rats. Brain Res 748:62-70.

Watanabe D, Inokawa H, Hashimoto K, Suzuki N, Kano M, Shigemoto R, Hirano T, Toyama K, Kaneko S, Yokoi M, Moriyoshi K, Suzuki M, Kobayashi K, Nagatsu T, Kreitman RJ, Pastan I, Nakanishi S (1998) Ablation of cerebellar Golgi cells disrupts synaptic integration involving GABA inhibition and NMDA receptor activation in motor coordination. Cell 95:17-27.

Wilson CJ, Groves PM (1980) Fine structure and synaptic connections of the common spiny neuron of the rat neostriatum: a study employing intracellular injection of horseradish peroxidase. J Comp Neurol 194:599-615.

Yung KKL, Bolam JP, Smith AD, Hersch SM, Ciliax BJ, Levey AI (1995) Immunocytochemical localization of $\mathrm{D}_{1}$ and $\mathrm{D}_{2}$ dopamine receptors in the basal ganglia of the rat: light and electron microscopy. Neuroscience 65:709-730. 